\title{
The Cultivation of Student's Critical Thinking Skills Based on English Reading Contest: A Case Study
}

\author{
Fenghuang ZENG \\ Foreign Language Department \\ Xiamen University Tan Kah Kee College \\ Zhangzhou, Fujian, China
}

\begin{abstract}
It is urgent to foster students' critical thinking in learning English, since the importance of critical thinking has been stressed and the absence of it has been noticed. One of the main purposes of "FLTRP.CUP" English Reading Contest is to foster contestants' critical thinking. This paper works out a systematic approach to prepare students for the Contest with an aim of fostering their critical thinking. The first step was to choose suitable students to set up a reading group. Then three students were selected to participate in the Provincial Final of “FLTRP.CUP” English Reading Contest by taking a school-level reading contest. Then four stages of English reading training were taken to enlarge students' vocabulary, broaden their horizons and foster their critical thinking skills. Students' self-evaluation and great performance in the Provincial Final Contest show that such a training mechanism is workable.
\end{abstract}

Keywords-cultivation of critical thinking skills; critical thinking; English Reading Contest; systematic approach

\section{INTRODUCTION}

With an ever increasingly fierce competition among individuals and nations, a consensus has been reached in modern society that critical thinking is really critical to the development of an individual and the future of a nation. According to Wen Qiufang [1], western countries have attached great importance to fostering students' critical thinking. For instance, American authority has ranged cultivation of students' critical thinking as a primary task and listed it one of the major goals of college education. By contrast, Chinese schools do not take enough action to develop students' critical thinking even though its importance has been greatly valued. Especially, there is an absence of critical thinking in English-major students [2]. And here is a similar situation for non-English major students when they learn English or do English reading. They spend too much time remembering the words and grammatical rules, analyzing the structure of the text and figuring out the meaning of the English materials they are reading about. Little time has been left for them to do critical thinking. This happens both in students' self-learning and the teaching of college English. The importance of critical thinking and the absence of it in college English learning and teaching have left us with no choice but to take immediate and visible measures to bridge the gap.

The "FLTRP.CUP” English Reading Contest is held for the purpose of arousing contestants' interest in English reading and fostering their critical thinking and logical thinking, which offers a new perspective to explore a practical way of fostering

This study was supported through Research Project on Foreign Language Teaching by Foreign Language Teaching and Research Press (20190501503). critical thinking in college English learning and teaching. This study tried to work on a systematic way of fostering students' critical thinking by preparing students for "FLTRP.CUP" English Reading Contest.

\section{THEORETICAL BASIS}

\section{A. Linguistic worldview}

The concept of linguistic worldview is put forward by Humboldt, who regards languages an essential element in the formation of worldview. According to his theory, every language embodies a unique worldview, which reflects the concepts, values and way of thinking of a nation [3]. Therefore, people who grow up in a certain circle of language and culture hold a different worldview from those growing up in another circle of language and culture [4]

An article or book is created by the author in his or her linguistic worldview influenced by his or her own culture. So the article or book tells a story of a particular culture and social background. When Chinese students read an English article or book written by a native speaker, they are communicating with the author coming from an alien culture. Therefore there may be a culture gap and space gap between Chinese readers and the English author, and even a time gap if the readers and the author do not live in the same era. English Reading Contest is in fact a second language reading competition. When Chinese students do the English reading, they tend to interpret the article or book with Chinese way of thinking, resulting in some kind of misunderstanding of the author's purposes. Therefore, when Chinese students do English reading, they should first learn how to think from the perspective of English worldview.

\section{B. Critical thinking and English reading}

John Newman [5] explains the idea of thinking in the book The Idea of a University that the true end of a University is not learning or acquirement, but thought or reason exercised upon knowledge. Those readers that read without thinking are only possessed and even carried away by their knowledge without any volition of their own. If we expect students to read well, we should encourage them to think well while reading. To think well in reading, they need to cultivate a reflective mind. According to Paul and Elder [6], excellence in thought or critical thinking can be cultivated. Critical thinking is the art of analyzing and evaluating thinking with a view to improving it. To foster critical thinking skills is in essence to foster traits of mind. Education contains the content which we want students to learn and acquire and the process during which students 
acquire the content in a deep and meaningful way. Critical thinking is the process part that helps students to acquire the content. Thinking cannot be separated from content. They are partners, not antagonists, because thinking needs content to think about while content is created by thought. It tells us something helpful in English reading, not only about the importance of recommending good and suitable books for students to read, but also about the matter of how to fuse cultivation of critical thinking into the process of reading English.

\section{PROCEDURE}

\section{A. Purpose of the study}

Ma Shuang [7] has done a survey and found that non-English majors from undergraduate students to doctorial students had a lack of reasoning and critical thinking competency when they spoke or wrote with English. What have led to the lack of basic proficiency in English and an absence of critical thinking on Chinese college students since they have learned English for more than ten years? Chinese students focus on acquisition of language in a mechanical way without paying enough attention to intercultural competency and critical thinking skills [8]. Many scholars in English education have been aware of this problem. According to Sun Youzhong [9], in China, foreign language education concentrates on language acquisition rather than liberal education; so, most of its teaching activities are conducted on the basis of imitation work, which reflects only a low-level way of thinking. Professor Wen Qiufang and her team have conducted an empirical research investigating the development of students' critical thinking skill and have constructed a measuring method for English majors to evaluate their critical thinking skill. Generally speaking, even though more and more scholars and teachers attach importance to fostering critical thinking, there is still a long way to go, especially in college English teaching and learning. It is a basic task for English learners to take command of English language skills, but it doesn't mean that language acquisition and knowledge acquisition cannot be welded. In the face of the fact that language acquisition has been separated from knowledge acquisition and development of critical thinking for our students when doing English reading, this study attempted to figure out a systematic way of fostering students' critical thinking in English reading by preparing students for the English Reading Contest. Therefore two questions were addressed in this paper: (1) How can we combine cultivation of critical thinking and English Reading Contest? (2) Can students benefit from preparing for the English Reading Contest?

\section{B. General procedure}

"A major barrier to the development of student thinking is the fact that few teachers understand the concept or importance of intellect engagement in learning [6]". Therefore, before instructing students to think critically, teachers who undertook training tasks were required to take command of relative theories, including linguistic worldview, critical thinking and intercultural communication, and to get a basic training on critical thinking, which were the necessary prerequisite to the cultivation tasks. Only when the teachers knew how to think critically and could think critically were they qualified to provide expert guidance.

When the teachers were ready for the task, they needed to select participants. In 2018, Forty-five students were selected from different majors around the college. The selecting criteria were based on their performance on English mid-term examination, English final examination and CET4. They were top students in English learning, and were passionate for English reading and eager to take part in reading contests. Then a training group was set up online and offline. After a period of instruction, while one student gave up, forty-four students from the group took part in the school-level English Reading Contest Three students who stood out in the performance were selected to participate in the Provincial Final of 2018 "FLTRP.CUP" English Reading Contest. When preparing the students for the Provincial Final of English Reading Contest, an intensive training plan was provided.

When the training began, the first thing the teachers needed to do was to address to the students the training objectives of fostering their critical thinking skills so as to increase their awareness of the cultivation of critical thinking. When students psychologically involved in learning, they were likely to obtain high levels of achievement [10]. Then a brief introduction to the basic theory and knowledge of critical thinking was given. Finally, the teachers chose suitable books for students to read. When choosing the books, some principles were kept. For example, those books that were easier and more familiar to students should be read before those difficult and unfamiliar ones. Different methods were introduced when guiding students to read, such as posing questions, discussion, debate, and writing. Specific examples will be provided in the next point.

\section{Training stages}

The test for "FLTRP.CUP” English Reading Contest concludes four parts as "Read and Know", "Read and Reason", "Read and Question", "Read and Create". Accordingly, the training was carried out through four stages. At the first stage, students were required to do extensive reading. They were required to finish reading articles selected from College English Extensive Reading Book 1 to Book 4. Those books were available, for they were part of the textbooks for College English. The subjects of the articles varied from history, philosophy, literature and education to environmental protection and science and technology. Students were encouraged to increase their vocabulary and broaden their horizons at this stage.

At the second stage, students were required to do reading comprehension online. The passages were chosen from TOEFL reading for the purpose of enlarging student's vocabulary and reasoning skill. The reading comprehension was put online with the aim of accustoming students to the computer-based test.

At the third stage, students were encouraged to learn to question. Reading is not only a kind of enjoyment, it is a process of thinking, exploring and adjusting. Reading helps people to know more, but reading without thinking is useless. Therefore, we encouraged students to think critically and to 
question bravely while reading. It was a pivotal part for the training work. For example, the first book required was The Guide to Critical Thinking by Linda Elder and Richard Paul. The book tells readers how to become a critical thinker. Then some articles and books were required. For example, The Necklace written by Guy de Maupassant was familiar to students. All students had learned the story in middle school, when they were often told that Madame Mathilde Loisel was vain and her husband was pathetic. But, students were required to re-read the story and judged the characters from modern perspectives. For instance, they were required to make a decision by imagining facing the same situation as Mathhilde and her husband. They were also required to justify Mathilde's actions in terms of her courage and honesty.

At the fourth stage, books chosen for the English Reading Contest by Foreign Language Teaching and Research Press were required to read carefully. Those books include various subjects, like literature and life, language and culture, society and human, philosophy and civilization, science and technology. They are helpful to increase students' knowledge, broaden their horizons and arouse their interest in English reading and useful to encourage them to think from new perspectives. For example, The Idea of a University written by John Henry Newman and The School and Society written by John Dewey were read and compared. Then students discussed and voiced their opinions on such questions as "What is the end of a university?" and "What do you think of your college?" The Discourses and Sayings of Confucius translated by $\mathrm{Gu}$ Hongming and Plato: A Very Short Introduction were read and compared. Students were encouraged to make a comparison between Chinese philosophy and Western philosophy, between Confucianism and Plato's thought and then to write down their ideas. Students were encouraged to build up their own ideas based on great people's. Writing based on reading and thinking could help them build up their own system of knowledge and thought. After that, students' written materials were read and discussed among the group. Communication and exchange of ideas would help them to enrich their thought and life. Meanwhile, students were also required to do writing exercise online. iWrite system was a useful platform for students to practice computer-based writing work.

\section{Evaluation}

The way of combining the cultivation of critical thinking and the English Reading Contest has been introduced in the previous point. As to evaluation, we made out a questionnaire for students to evaluate the progress they had made as the first step of evaluation. Twenty-five students from the training group did the questionnaire. Some students gave up after getting low scores in the school-level English Reading Contest. Five questions were presented.

(1) What was the main barrier to your English reading when you did the reading test for the school-level reading contest?

(2) Do English reading contests focus on evaluating student's reasoning and critical thinking skills?

(3) Are you willing to get further training on English reading?
(4) Does the training work improve your critical thinking skill and will help you get better performance in the contests?

(5) Does the cultivation of critical thinking be combined well with and benefit from the English reading contests?

As to the first question, 84\% participants regard reasoning and critical thinking skills as the main barrier to their English reading while $16 \%$ participants choose English language ability The tests for the English reading contest focus on examining contestants' reasoning and critical thinking skills. The result tells us that the contests are helpful to arouse the contestants' awareness of fostering reasoning and critical thinking skills. Meanwhile, we can learn from the result that English language ability is also essential that it cannot be neglected. As to the second question, 96\% participants deem that English reading contests do concentrate on examining contestants' reasoning and critical thinking skills. According to question three and question four, all participants express their willingness to get some training to improve critical thinking skill, for they have realized the importance of the skill and the absence of it on them. As to the fifth question, 92\% participants think that English reading contests and cultivation of critical thinking can be combined and benefit each other.

The three students who stood out from the school-level competition took part in Fujian Provincial Final of 2018 "FLTRP Cup" English Reading Contest after receiving the systematic training and gained a satisfactory achievement. One was the winner of the grand prize, one the first prize and one the second prize. The achievement showed that the systematic approach of combining the cultivation of students' critical thinking and "FLTRP.CUP" English Reading Contest was workable.

\section{CONCLUSION}

When Chinese students learn English, they lay stress on language skills without giving enough attention to intercultural communication and cultivation of critical thinking. The result is that most college students don't reach the standard of proficiency in English. They can't speak fluently or write logically. Professor Huan Yuanshen [12] called for a reform of English teaching to improve Chinese students' critical thinking skill while doing language learning. To achieve a similar purpose, "FLTRP.CUP" English Reading Contest emerged. This study attempted to work out a systematic approach to foster students' critical thinking based on preparing them for the Contest.

The test for the Contest is made up of four parts to examine contestants' reasoning and critical thinking skills. According to the data collected from the questionnaire, most of the participants consider it useful to foster students' critical thinking in a systematic way with practical measures. And the great performance in Provincial Final of 2018 "FLTRP.CUP" English Reading Contest indicated that students have made progress both in their language ability and critical thinking competency by preparing for the Contest. Meanwhile, it was not only beneficial to students, but also to teachers. Undertaking the training work has enabled teachers to understand the foundations of critical thinking, encouraged them to think critically and helped them to make better 
teaching plans for the teaching of college English. Therefore, the same approach has been used in selecting and training work for the 2019 “FLTRP.CUP” English Reading Contest.

However, there is no a practical and suitable measuring mechanism to evaluate to what extent the students and teachers have benefited from preparing for the reading contests, yet, that is what we are committed to in the future study.

\section{REFERENCES}

[1] Wen Qiufang, A study on the critical thinking skills of foreign language majors at Chinese universities. Beijing: Foreign Language Teaching and Research Press, 2012, pp. 3-4. (In Chinese)

[2] Huang Yuanshen, Absence of critical thinking. Foreign Language and Their Teaching, 1998, No.7, pp.1,19. (In Chinese )

[3] Pan WenGuo, Contrastive work between Chinese and English. Beijing: Beijing Language and Culture University Press, 2014, pp. 27-35. (In Chinese)

[4] Wu Tieping, Language as an advanced science. Beijing: Beijing Language and Culture University Press, 1994, pp. 37. (In Chinese)
[5] John H. Newman, The Idea of a University. Beijing: China Renmin University Press, 2012, pp. 128-129.

[6] Richard Paul, and Linda Elder, Critical Thinking Competency Standards Beijing: Foreign Language Teaching and Researching Press, 2018, pp.4-6.

[7] Ma Shuang, Deep Analyses of the Root of the Chinese College Students' "Syndrome of Absence of Critical Thinking" as well as the Counter-measures: Taking College English Education as an Example. Foreign Language and Literature, 2018, vol. 34, No.1, pp. 140-146. (In Chinese)

[8] He Qixin, Yin Tongshen, Huang Yuanshen, and Liu Hai Ping, Suggestions on reform of undergraduate education for foreign language majors. Foreign Language Teaching and Research, 1999, No.1, pp.24-28. (In Chinese)

[9] Sun Youzhong, Foreign language education and cultivation of critical thinking skills. Foreign Languages in China, 2015, Vol. 12, No.2, pp. 23. (In Chinese)

[10] Teng Feng, Development of morphological awareness through English songs: a case study. Chinese Journal of Applied Linguistics, 2016, Vol.39, No. 2, pp.167-184.

[11] Huang Yuanshen, Education reform of foreign language courses should be carried out - about absence of critical thinking. Foreign Language World, 2010, No.1, pp. 11-16. (In Chinese) 